BULLETIN Bulletin hispanique

HispaniquE Université Michel de Montaigne Bordeaux

114-1 | 2012

Varia

\title{
Producción de presencia y auto-representación profética
}

Notas sobre la poesía del frente a propósito de Viento del pueblo (1937)

de Miguel Hernández

\section{Mario Martín Gijón}

\section{(2) OpenEdition}

Journals

Edición electrónica

URL: http://journals.openedition.org/bulletinhispanique/1856

DOI: 10.4000/bulletinhispanique.1856

ISSN: 1775-3821

Editor

Presses universitaires de Bordeaux

\section{Edición impresa}

Fecha de publicación: 1 junio 2012

Paginación: 263-276

ISBN: $978-2-86781-812-7$

ISSN: 0007-4640

Referencia electrónica

Mario Martín Gijón, «Producción de presencia y auto-representación profética », Bulletin hispanique [En línea], 114-1 | 2012, Publicado el 01 junio 2015, consultado el 19 abril 2019. URL : http://

journals.openedition.org/bulletinhispanique/1856; DOI : 10.4000/bulletinhispanique.1856 


\title{
Producción de presencia y auto-representación profética. Notas sobre la poesía del frente a propósito de Viento del pueblo (1937) de Miguel Hernández
}

\author{
Mario MarTín Gijón \\ Universidad de Extremadura
}

En partant du livre de poèmes Viento del pueblo (1937) de Miguel Hernández, ce travail vise à analyser les traits principaux de la poésie écrite sur le front républicain pendant la guerre d'Espagne. Cette poésie sinscrit dans une "culture de la présence " définie par la centralité du corps, l'intégration de l'homme dans la nature et une définition prophétique du métier de poète.

Este artículo pretende, partiendo del poemario Viento del pueblo (1937) de Miguel Hernández, analizar los rasgos de la poesía escrita en los frentes de combate de la España republicana durante la guerra civil: poesía que se integra dentro de una "cultura de la presencia» definida por la centralidad del cuerpo, la integración del hombre en la naturaleza y una definición profética del oficio de poeta.

Based on Miguel Hernández's poems book Viento del pueblo (1937), this paper analyses the main features of the poetry written during the Civil War, on the Republican front of Spain, poetry that fits in a "presence culture", including features like body centrality, the integration of man in nature, and a prophetic definition of the poet.

Mots-clés : poésie du XX $\mathrm{XX}^{\mathrm{e}}$ siècle, Miguel Hernández, guerre d'Espagne, signe poétique.

S Alvo raras excepciones, la poesía escrita en la República española durante $\checkmark$ la guerra civil ha sido considerada por la crítica como un testimonio de gran valor histórico pero de escaso valor estético, lastrada inevitablemente por las circunstancias. De este menosprecio generalizado suelen excluirse algunos libros escogidos, como España en el corazón, de Pablo Neruda, España aparta 
de mi este cáliz, de César Vallejo o Viento del pueblo, de Miguel Hernández, así como la literatura surgida en «el grupo de Hora de España».

Sin embargo, tratar obras como la "Ponencia colectiva», los ensayos de Juan de Mairena o El hombre y el trabajo de Serrano Plaja como las excepciones a una literatura caracterizada por los excesos partidistas y la escasa exigencia formal, conlleva una confusión que podríamos evitar si partimos de una dicotomía que resulta operativa para todos los géneros, entre el espacio de producción del frente y el espacio de producción de retaguardia ${ }^{1}$. Esta división se comenzó a forjar desde las primeras semanas de guerra, al haber escritores que se alistaban como milicianos y otros que pasaron a desempeñar labores administrativas o de propaganda en la retaguardia. El traslado de los órganos de gobierno de la República a Valencia, así como de un selecto grupo de intelectuales a los que se irían añadiendo otros, poco deseosos de permanecer en el frente, contribuiría a asentar una división dentro del campo literario que ya había venido apuntándose desde el principio, entre los autores que desarrollaron la mayor parte de su actividad en la retaguardia y aquéllos que, integrados dentro del Ejército, llevaron a cabo su labor en unas circunstancias de excepción que conformaron una de las más originales definiciones de praxis literaria que se han dado. Y es que, como veremos, la poesía de los frentes de guerra tuvo unos rasgos que la distinguían netamente de la producida en la retaguardia.

En el nivel más visible, la poesía del frente se caracterizó, en primer lugar, por estar ligada a una amplísima campaña de extensión cultural, que logró la alfabetización y formación cultural de decenas de miles de combatientes, así como por su subordinación al poder político y militar y las necesidades de la guerra, como muestra Miguel Hernández en su «Carta abierta a Valentín González "El Campesino"»: "Yo seré el poeta dispuesto a empuñar el fusil y a empuñar el romance cuando lo creas conveniente» ${ }^{2}$. La conjunción de educación, expansión cultural y adoctrinamiento político está presente desde el principio en la figura del comisario político que desempeñó Miguel Hernández. Esta poesía, como es natural, se vio plenamente condicionada por sus lectores previstos, que eran los propios combatientes, y se difundió predominantemente mediante la prensa de guerra.

Por el contrario, la poesía surgida en el entorno de la Alianza de Intelectuales Antifascistas y, sobre todo, a partir de enero de 1937, alrededor del grupo de Hora de España, se caracterizó por una clara voluntad de autonomía respecto al poder político, expuesta teóricamente en la célebre «Ponencia colectiva» y por una necesidad de sus integrantes de distinguirse respecto a la poesía producida en los frentes de guerra, especialmente frente a los romances que se escribían por millares.

1. Al hablar de «espacio de producción» sigo un concepto espacial del «campo literario» como todo el conjunto de agentes que intervienen en la producción, difusión y valoración de la obra literaria: escritores, críticos, editores y público. Véase Pierre Bourdieu, Les règles de l'art. Genèse et structure du champ littéraire, París, Éditions du Seuil, 1992.

2. Miguel Hernández, Obra completa, vol. 2. Teatro. Prosas. Correspondencia, edición crítica de José Carlos Rovira y Agustín Sánchez Vidal, Madrid, Espasa-Calpe, 1992, p. 2186. 
Miguel Hernández se alistó, el 23 de septiembre de 1936, en el Quinto Regimiento, que sería tomado como modelo a la hora de crear el Ejército Popular, y que se caracterizó desde el principio por el fomento de la formación cultural de los combatientes ${ }^{3}$. A pesar de esta incorporación relativamente tardía, provocada por sus conocidas circunstancias personales (noviazgo con Josefina Manresa, asesinato del padre de ésta por milicianos), Hernández llegaría a representar, como nadie, la figura del «poeta combatiente», especialmente a raíz de Viento del pueblo (1937), la obra más representativa de la integración de Hernández en la cultura del frente, y que recoge poemas anteriormente aparecidos en la prensa del frente. Este poemario puede considerarse, en palabras de Leopoldo de Luis, como «el más alto exponente de la poesía de combate que produjo la guerra civil ${ }^{4}$ por lo que resulta un modelo excepcional para delimitar las cualidades diferenciales de la poesía del frente.

Antes de seguir con la descripción de la praxis poética en los frentes de guerra, parece necesario hacer algunas puntualizaciones metodológicas, pues la insatisfactoria percepción estética de los romances de guerra, debería suscitar una reflexión sobre nuestros instrumentos heurísticos para abordar esta poesía. Serge Salaün, sin duda el estudioso más cualificado del Romancero de la guerra civil, reconoció en cierto momento que este auge poético había adoptado unas formas para las cuales los instrumentos de análisis que un acercamiento semiótico ofrecía, resultaban insuficientes ${ }^{5}$. Esta insuficiencia frustrante para el análisis se debe, en mi opinión, al hecho de que estos poemas han sido siempre abordados desde una perspectiva hermenéutica basada exclusivamente en la extracción de sentido.

Por ello, en este estudio se pretende introducir otra dimensión del signo poético, que ha sido desatendida hasta tiempos recientes. Me refiero a la dimensión de "presencia», analizada exhaustivamente por Hans Ulrich Gumbrecht para analizar una serie de fenómenos que no pueden ser explicados dentro del campo tradicional de la hermenéutica: esto es, mediante la adjudicación de significado o sentido. La "presencia» designa una relación espacial respecto al mundo y sus objetos. Lo que es presente debe ser palpable, lo que implica a su vez, que puede influir sobre los cuerpos humanos ${ }^{6}$. Esta dimensión comienza a cobrar importancia a medida que el paradigma dualista entre res cogitans y res corporea, alma y cuerpo, consagrado por René Descartes va perdiendo vigencia en una sociedad secularizada y donde al mismo tiempo el

3. José Herrera Petere, incorporado desde los primeros días al Quinto Regimiento, lo recuerda, en su novela Acero de Madrid, haciendo cola para alistarse en el famoso cuartel de Francos Rodríguez: «En una cola, como un miliciano más, estaba el nuevo poeta: Miguel Hernández». José Herrera Petere, Obras Completas. Narrativa I, edición de Dolores Gimeno Puyol. Guadalajara, Diputación de Guadalajara y Junta de Castilla-La Mancha, 2009, p. 248.

4. Leopoldo de Luis, Aproximaciones a la obra de Miguel Hernández, Madrid, Libertarias/ Prodhufi, 1994, p. 44.

5. Serge Salaün, «La guerre d'Espagne ou l'épopée du signe», Imprévue IX, 2, 1986, p. 35.

6. Hans-Ulrich Gumbrecht, Diesseits der Hermeneutik. Die Produktion von Präsenz, Fráncfort del Meno, Suhrkamp, 2004, pp. 9-11. 
cuerpo va imponiendo sus valores, como muestra el auge del deporte. En 1926 se había publicado Sein und Zeit, donde Martin Heidegger rebatía la ontología cartesiana como «una determinación errónea del mundo» que incluso habría supuesto un retroceso frente a la elaboración escolástica del problema del ser, y apuesta por una definición de existencia en la que la espacialidad supone una revaloración de la corporalidad ${ }^{7}$. Las formas propias de lo que Gumbrecht llama "culturas de significado", en las que domina una concepción del signo como unión de un significante material con un significante espiritual, van dejando paso a formas propias de las «culturas de presencia», donde se evita esta separación, y donde rige una concepción del signo más cercana a la tradicional idea de Aristóteles como la unión de una sustancia (algo que necesita espacio) y una forma, que hace posible que esta sustancia sea percibida.

Esta concepción del signo había ido ganando fuerza a medida que se imponía lo que se suele llamar «rehumanización del arte» y no parece casual que, cuando Luis Felipe Vivanco escriba "La desesperación en el lenguaje» (1933), reseńa a Residencia en la tierra de Pablo Neruda, poeta decisivo en la poética hernandiana y en la definitiva imposición de un discurso poético etiquetado como "impuro", lo haga bajo un claro influjo heideggeriano, y llegue a anticipar ideas similares a las que el pensador alemán elaboraba por entonces y reuniría en Der Ursprung des Kunstwerkes (1936). Parece claro que desde finales de los años 20 y de manera más pronunciada durante los años 30 , se sintió de manera cada vez más irreprimible una necesidad de apertura y de exposición existencial, de producir el efecto o la ilusión de la llegada a la presencia del "corazón de las cosas», que Jean-Luc Nancy describe como "a concentration of all motion, tender or violent, joyous or anguished, tender and violent, joyous and anguished ${ }^{8}$. Esta necesidad de exponerse existencialmente explica el rápido descrédito de lo que se llamó «literatura deshumanizada», la llegada del surrealismo y el rápido proceso de adopción de un compromiso político por la mayoría de los escritores. $Y$ es que, a pesar de la ya numerosa bibliografía sobre las transformaciones del discurso vigente en el campo literario español durante los años treinta, falta discernir cómo, bajo todas las proclamas de «nuevo romanticismo», «rehumanización» o «marcha al pueblo», lo que hay es un cambio de paradigma, por el cual la concepción dualista del signo que había dominado la cultura occidental hasta entonces, deja paso a una concepción del signo como forma que contiene una sustancia de manera inseparable, impulsando una revaloración del cuerpo y una necesidad de "crear presencia», tanto en el arte como en la política.

Este proceso culmina en la literatura producida en los frentes de guerra. Aunque, obviamente, cultura de presencia y cultura de significado son dos abstracciones, ya que en cada cultura existen los elementos propios de ambas en distinta proporción, creo que la presencia masiva de elementos de producción de presencia en las obras literarias del frente contribuyen a formar un discurso

7. Martin Heidegger, Sein und Zeit, Tubinga, Max Niemeyer Verlag, 2001, pp. 95 y 108.

8. Jean-Luc Nancy, The Birth to Presence, Stanford, Stanford University Press, 1993, p. 171. 
claramente delimitado, en algunos aspectos muy diferente a la literatura producida en la retaguardia, como se puede ver repasando los rasgos que Gumbrecht enuncia como propios de las culturas de presencia?

En primer lugar, en las culturas de presencia, la auto-referencia principal es el cuerpo, frente a la posición principal de la mente, o el espíritu, en las culturas de significado ${ }^{10}$. En los poemas de guerra, puede registrarse una verdadera "rhétorique du corps», que Claude Le Bigot reduce al paradigma «latido, pulso, fiebre, corazón, vena, sangre»" ${ }^{11}$ y que Miguel Hernández desarrolló hasta sus últimas consecuencias, tanto al expresar sus sentimientos como al percibir al pueblo en lucha siempre corporal. Así, en «Sentado sobre los muertos», incita al pueblo a que "castigu[e] a quien te malhiere / mientras que te queden puños, / uñas, saliva, y te queden / corazón, entrañas, tripas, / cosas de varón y dientes» ${ }^{12}$. Ya Ramón Gaya, en su reseña de Viento del pueblo hablaba del «delirio materializador» ${ }^{13}$ del poeta oriolano y, como demostró minuciosamente Serge Salaün, el área semántica del cuerpo domina completamente la poesía de Hernández, de modo que, por ejemplo, en el poemario que nos ocupa, frente a las 45 veces que aparece «sangre», las 38 de «mano» y las 35 de «corazón», la palabra «alma» aparece en unas 24 ocasiones, y los «ojos», tradicionalmente considerados la parte más espiritual del cuerpo, sólo unas 17 veces ${ }^{14}$. Como explica el profesor bretón, «el hombre dialoga con los demás y con el mundo gracias a todo su cuerpo, sus miembros, sus vísceras, su piel ${ }^{15}$, por lo que no sólo lo espiritual adquiere consistencia, de modo que el nińo yuntero tiene "un alma color de olivo» y el poeta un «alma de encina», sino que el léxico corporal llega a colonizar ámbitos tradicionalmente teñidos de espiritualidad, en fórmulas muy llamativas como «la mano del corazón» o «los cojones del alma». Hernández, desengañado poco antes de su primera religiosidad, se vuelca en un culto a lo corporal, cargado positivamente, de modo que incluso el lenguaje ha de ser reforzado con elementos corporales. Así, en «Llamo a la

9. Un esbozo de lo que se expondrá lo adelanté de manera forzosamente esquemática en un trabajo en el que analizaba la poesía de guerra de tres autores tan diferentes como Vallejo, Prados y Petere. Véase Mario Martín Gijón, «Verbreitung des Diskurses und Produktion der Präsenz. Das sprachliche Zeichen in der Dichtung des Spanischen Bürgerkrieges am Beispiel von José Herrera Petere, Emilio Prados und César Vallejo», Zeichen setzen. Konvention, Kreativität, Interpretation. 24 Forum Junge Romanistik 2008, ponencia inédita.

10. Gumbrecht, op. cit., p. 100.

11. Claude Le Bigot, L'encre et la poudre. Pour une sémantique de l'engagement dans la poésie espagnole sous la II. République (1931-1939), préface de Francisco Caudet. Toulouse, Presses Universitaires du Mirail, 1997, p. 65.

12. Miguel Hernández, Viento del pueblo. Poesía en la guerra, edición de Juan Cano Ballesta, Madrid, Cátedra, 1989, p. 64.

13. Ramón Gaya, «Divagaciones en torno a un poeta: Miguel Hernández», Hora de España, no 17 (avril-juin 1938), p. 48.

14. Serge Salaün, «Miguel Hernández: Eros en la guerra (Viento del pueblo)», Francisco Javier Díez de Revenga y Mariano de Paco, dir, Estudios sobre Miguel Hernández, Murcia, Universidad de Murcia, 1992, p. 437.

15. Ibid., p. 438. 
juventud», para que los jóvenes de España asuman una promesa se pide que pongan «estas palabras, mordiéndolas, / en lo mejor de sus dientes» ${ }^{16}$.

Relacionada con esta preeminencia de lo físico está la frecuente alusión a la virilidad, fácil pero efectivo recurso dirigiéndose a los destinatarios soldados y que conlleva una clara división sexual del trabajo, recurriendo a las acusaciones de afeminamiento para quienes no cumplen con sus deberes de soldado, como en «Los cobardes». Esta dominación masculina ni siquiera se desmiente en un poema como "Rosario, dinamitera», pues el mayor elogio que se le hace a la miliciana es que "puedes ser varón» ${ }^{17}$. Por lo tanto, nada sorprendente que, desde el espacio de retaguardia, en el que regían los habituales modos de distinción del intelectual, Ramón Gaya reprochara a Miguel Hernández «esa maniática preocupación por conseguir poesía masculina y fuerte» ${ }^{18}$.

En segundo lugar, mientras que en una cultura de sentido, el sujeto y la subjetividad, depositarios de la espiritualidad, ocupan una posición separada y excéntrica al mundo, considerado como compuesto por objetos materiales, en una cultura de presencia, los hombres consideran que sus cuerpos forman parte de una cosmología; es decir, no se sienten enfrentados al mundo sino parte de él, en armonía con la naturaleza. Nada más alejado del romanticismo, en este sentido, que los poemas escritos en los frentes de guerra, los cuales, como señalara Serge Salaün, «son poemas nacidos [...] bajo el "stimulus" de una peripecia exterior al YO pero en el cual el YO se descubre y se integra» ${ }^{19}$. De manera lógica, en el discurso del frente, el individuo es considerado casi siempre como parte de una entidad mayor: su tierra, su oficio, su clase social. Por ejemplo, en «Vientos del pueblo me llevan», la individualidad de cada combatiente es subsumida dentro de su región de procedencia, caracterizada sumariamente por un atributo de su idiosincrasia, su clima o su dedicación laboral predominante: «Asturianos de braveza, / vascos de piedra blindada, / valencianos de alegría / y castellanos de alma, / [...] extremeños de centeno, / gallegos de lluvia y calma». En la poesía del frente, el destinatario es absorbido por la comunidad y ésta por la naturaleza en la que se integra, de modo que las juventudes «brotan de la encina» y los andaluces de Jaén están indisolublemente unidos a los olivos ${ }^{20}$. Y es que, como dijo Salaün, sobre todo durante los primeros meses de la guerra civil se extendió la creencia de que «el mundo entero es el que está en juego, el destino humano en armonía con las fuerzas físicas que vehiculan la más auténtica metafísica»". Así, no sólo son dignificados «los cuerpos que mueven sus miembros trabajados / como constelaciones» sino incluso las secreciones como el sudor, al que Hernández dedica uno de sus poemas más visionarios,

16. Miguel Hernández, op. cit., p. 79.

17. Ibid., p. 90.

18. Gaya, op. cit., pp. 49-50.

19. Serge Salaün, «Miguel Hernández: Individualidad y colectividad», en Juan Cano Ballesta y otros, En torno a Miguel Hernández, Madrid, Castalia, 1978, p. 199.

20. Hernández, op. cit., pp. 66 y 85.

21. Serge Salaün, «Miguel Hernández: Individualidad y colectividad», p. 202. 
en el que el sudor de los campesinos los une con los ciclos del agua, pues «[e] $\mathrm{n}$ el mar halla el agua su paraíso ansiado / y el sudor su horizonte, su fragor, su plumaje» y con los ciclos agrarios estacionales, pues el sudor «deja rodando por las eras, / del abril al octubre, del invierno al verano / áureas enredaderas» ${ }^{22}$.

La cultura de presencia, por otra parte, al fundir al individuo en una comunidad, minimiza el significado de la muerte individual, considerada como fase inevitable de los ciclos naturales. Así surge lo que Johannes Lechner llamó el tópico de "la muerte que fecunda»" ${ }^{23}$, presente en la poesía de guerra de otros poetas como Rafael Alberti o José Herrera Petere, y por el que la muerte del soldado, considerado no en su individualidad sino en su función dentro de la masa, es presentada como sacrificio que engendra el futuro. Así, en "Nuestra juventud no muere», desde su primer verso, "Caídos sí, no muertos, ya postrados titanes», se niega lo trágico de la muerte de los heroicos soldados: "No hay nada negro en estas muertes claras» ${ }^{24}$. En el uso de este tópico, los poetas se sirven descaradamente de las connotaciones de naturalidad de los campesinos, que formaban el contingente mayor del Ejército popular. Así, el poeta se dirige a los «señores de la labranza, / hombres que entre las raíces, / como raíces gallardas, / vais de la vida a la muerte, / vais de la nada a la nada", incitándoles a abonar, con su supremo sacrificio, los campos de la patria: «Echa tus huesos al campo, / echa las fuerzas que tienes / a las cordilleras foscas / y al olivo del aceite» ${ }^{25}$.

Sin embargo, esta percepción del combatiente se basa en razones de pertenencia social que, a pesar de toda la voluntad del poeta alicantino de meterse "pueblo adentro" ${ }^{26}$, subsisten entre él y los «hombres elementales», como los llamara Gil-Albert ${ }^{27}$, lo cual se pone de manifiesto si se compara el tratamiento de la muerte anónima, cumplimiento de un ciclo natural inevitable, con la "Elegía primera» dedicada a la muerte de Federico García Lorca, y en la que la muerte del poeta granadino no sólo es vista en su condición irremediable e injustificada sino que es presentada como un acontecimiento que quiebra la

22. Hernández, op. cit., pp. 107-108.

23. Johannes Lechner, El compromiso de la poesía española del siglo XX. Parte primera. De la generación de 1898 a 1939, Leiden, Universitaire Pers Leiden, 1968, pp. 162-163.

24. Hernández, op. cit., pp. 77-78.

25. Ibid., pp. 67 y 82. Marie Chevallier registró en Hernández «una visión de la muerte como reintegración en la fuente material de toda vida y de toda fecundidad que ella representa» y «un verdadero materialismo místico", en Marie Chevallier, Los temas poéticos de Miguel Hernández, Madrid, Siglo XXI, 1978, pp. 302 y 305. Por supuesto, ambos rasgos no son exclusivos del oriolano, sino que corresponden a la cultura de presencia que se impuso en los frentes de guerra de la España republicana.

26. Hernández, Obra completa, p. 1787.

27. Juan Gil-Albert, «El poeta como juglar de guerra», Nueva Cultura, III, 1 (marzo 1937), p. 252. Tradicionalmente, como analizara Pierre Bourdieu, el campesinado, muy rara vez sujeto de su destino, ha servido como una "clase objeto» dotada de unas connotaciones de proximidad a la naturaleza frente a las cuales se distinguen las otras clases. Pierre Bourdieu, «Une classe objet», Actes de la Recherche en Sciences Sociales, 17-18 (novembre 1977), pp. 2-5. 
naturaleza: «Muere un poeta y la creación se siente / herida y moribunda en las entrañas. / Un cósmico temblor de escalofríos / mueve terriblemente las montańas, / un resplandor de muerte la matriz de los ríos ${ }^{28}$.

Con ello se remarca el carácter profético y cercano a lo divino que adoptó el oficio de poeta en el frente, y que está relacionado con la concepción del conocimiento que domina en las culturas de presencia. Si en las culturas de significado, el conocimiento es obtenido por un sujeto mediante un acto de interpretación del mundo, en las culturas de presencia, el conocimiento es normalmente conocimiento revelado, recibido por el sujeto, ligado a la magia. Aunque cabría prever que una ideología laica y racionalista como la que sustentaba el discurso frentepopulista resultara incompatible con una concepción similar del conocimiento a la que domina en las culturas de presencia, pueden encontrarse numerosos ejemplos en los que el poeta conjura la naturaleza para que contribuya a la victoria. Así, poetas tan diferentes como Juan Gil-Albert y José Herrera Petere se dirigen al río Turia y al río Alberche, respectivamente, y Miguel Hernández, en «Fuerza del Manzanares» invoca al humilde río madrileño, agrandado hiperbólicamente por su función defensiva frente a las tropas fascistas: «El leve Manzanares se merece / ser mar entre los mares [...]. / Tus aguas de pequeńa muchedumbre, / ay río de Madrid, yo he defendido, / [...] Al río Manzanares lo hace crecer la vena / que no se agota nunca y enriquece. / [...] El alma de Madrid inunda las naciones, / el Manzanares llega triunfante al infinito, / pasa como la historia sonando sus renglones, / y en el sabor del tiempo queda escrito ${ }^{29}$.

La escritura de un poema como éste no tendría ninguna función si no existiera una enorme confianza en el lenguaje, basada en la inextricable fusión entre forma y contenido que domina en la concepción del signo que se ha impuesto, y que funda la inquebrantable fe que en el poder de las palabras predomina en los frentes de guerra durante la guerra civil española. El lenguaje ejerce una acción performativa en la mente de los participantes (autor y receptores). Como apunta Vera Abadía, «la convicción, las apelaciones emocionales y un perfecto manejo del lenguaje trabajan a su favor; produciéndose una total simbiosis entre el poeta, el lenguaje, el paisaje y su ideario. "Aceituneros", "Jornaleros", o "Campesino de España", "El niño yuntero" [...] llevan al lector a una especie de estado catártico»" ${ }^{30}$. El signo poético, el poema, se considera inseparablemente unido a la realidad. Esta praxis poética, en la que el poeta pretende influir sobre los elementos no está lejos de las canciones de intención mágica en la literatura oral de los pueblos primitivos y resulta muy característica de la integración del hombre en la naturaleza ${ }^{31}$. Y es que estos poemas tienen su razón de ser

28. Hernández, Viento del pueblo, pp. 59-60.

29. Ibid., pp. 130-132.

30. Manuel Ramón Vera Abadía, «Miguel Hernández en el laberinto de la guerra civil», Anthropos, 220 (2008), pp. 45.

31. Ya Juan Cano Ballesta, relacionó acertadamente esta visión con «los motivos centrales de las religiones primitivas y arcaicas fundadas en la sacralidad de la vida orgánica». Juan Cano Ballesta, La poesía de Miguel Hernández, Madrid, Gredos, 1962, p. 66. 
en la recitación pública, donde el poeta aparece frente a la comunidad militar como profeta que conjura a los elementos y que despierta la emoción y la creencia en la victoria. Como dice Eutimio Martín, los poemas que forman Viento del pueblo fueron escritos "primero para ser recitados en público, y luego publicados y, al final, editados para su lectura en privado ${ }^{32}$. Nada extraño, por tanto, que el poemario tenga un "carácter manifiestamente oral $»^{33}$. Sólo una lectura descontextualizada de estos poemas puede censurar en ellos «el énfasis oratorio» como "el peor aspecto convencional de [estos] poemas»" ${ }^{34}$, ya que sabemos que, si el poema escrito para la lectura solitaria suele ser sintético en la idea y subordinado en la expresión, la poesía oral, o la poesía escrita para convertirse en "escritura proferida ${ }^{35}$, suele tener un carácter aditivo, agregativo, redundante, copioso ${ }^{36}$.

Así, la convivencia del poeta con los soldados en el frente conlleva una transformación en la función del poeta, que ya no es sólo el productor de un texto, sino que se encarga también de representarlo frente a un público con el que pretende identificarse y en nombre de quien pretende hablar. Se asiste a la aparición de una teatralización del poema, proferido en recitales públicos. La evolución del discurso vigente en el campo literario iba en esta dirección: el poema, escrito cada vez más en función de la situación comunicativa, ligado a una finalidad concreta y temporal, se convierte en «acontecimiento", "suceso», más aun cuando el poeta puede dotar, por sus dotes recitativas y gestuales, de mayor fuerza al poema, como reconocería Tomás Navarro Tomás, a pesar de su representación algo tópica, en su prólogo al poemario que nos ocupa:

En el efecto de sus recitaciones, las cualidades de su estilo hallan perfecto complemento en las firmes inflexiones de su voz, en su cara curtida por el aire y el sol [...] y hasta en el carácter de su dicción, fuertemente marcada con el sello fonético del acento regional. Sus ademanes son sobrios y contenidos y su expresión enérgica, grave y concentrada. Hay una ardiente exaltación en el recogimiento de su gesto y en la fijeza e intensidad de su mirada ${ }^{37}$.

Otros testimonios confirman esta percepción, por ejemplo el de Santiago Álvarez, comisario político de la 11 División a la que se incorporó el oriolano, para quien «él no era como Rafael Alberti o como los otros que iban al frente, estaban en un acto y volvían a Madrid. Él estuvo allí todo el tiempo, igual que cualquier otro combatiente [...] los soldados le querían mucho: dormía con ellos, comía con ellos y segundo, porque era un gran poeta, hacía poesías que

32. Eutimio Martín, El oficio de poeta. Miguel Hernández, Madrid, Aguilar, 2010, p. 463.

33. José M. Balcells, Miguel Hernández, corazón desmesurado, Barcelona, Dirosa, 1975, p. 161.

34. Marie Chevallier, La escritura poética de Miguel Hernández, Madrid, Siglo XXI, 1977, p. 311.

35. Paul Zumthor, Introduction à la poésie orale, Paris, Seuil, 1983, p. 163.

36. Walter J. Ong, Orality and Literacy. The Technologizing of the Word, Londres, Routledge, 2002, pp. 36-57.

37. Hernández, Viento del pueblo, p. 54. 
llegaban mucho al fondo $»^{38}$. También Pedro Mateo Merino, que coincidió con Hernández en la 1 ${ }^{\text {a }}$ Brigada Móvil de Choque, comandada por «El Campesino», recordaba que "nos producía una gran impresión [...] el aspecto sencillo de aquel muchacho campesino, su entusiasmo, su inspiración, la hermosura de los versos que recitaba allí para todos nosotros [...]. Tenía además la virtud de hacerse entender; y de llegar a la gente con un estilo sencillo, directo, entusiasta, mostrando la capacidad esa de comprender a los demás y tratar de ponerse a su alcances ${ }^{39}$.

Por lo tanto, parece claro que, durante el primer año de guerra, Miguel Hernández se sintió plenamente integrado en el Ejército popular y en la cultura del frente, y distanciado tanto de los escritores de la Alianza de Intelectuales Antifascistas como del exquisito grupo en torno a Hora de España, hasta el punto de arremeter duramente contra los modos y las iniciativas culturales de retaguardia, percibidas como señoritismo, en su prosa «Defensa de Madrid»:

cuando los hombres del pueblo [...] están viviendo en las trincheras unos días inacabables de hambre, fuego y muerte, sin dormir [...] con las ropas mojadas de barro, de sangre, de lluvia [...] veo, siento con pesadumbre y cólera ciudades de retaguardia ajenas, ajenas por completo, a pesar de sus aparatos de carteles y carteleros de propaganda, a la terrible verdad que nos circunda. Dentro de ellas no hay otra cosa que carne de carnaval, fingimiento de problemas importantes, burocracia, problemillas, torpezas y mezquindades que hacen apretar los dientes y el alma. No puede ser. Hemos de acabar con ese disfrazado fascismo de orgías, de cobardes resentidos, de señoritos que no podían serlo y lo son en cuanto pueden ${ }^{40}$.

La pertenencia a la cultura del frente, que alcanzó su mayor definición en los escritores ligados al Partido Comunista, le hace oponer, en otra prosa, «la Espańa joven y jornalera», caracterizada por su austeridad, con quienes "pretenden establecer una nueva burguesía, viciar y deshonrar con preferencias y halagos la moral de sencillez y hombría que impone el comunismo» ${ }^{41}$.

Como vamos viendo, el objetivo principal de los poemas que forman Viento del pueblo no era «dar cuenta poética del significado más profundo de la experiencia bélica» ${ }^{42}$, algo que sí pretendían los redactores de Hora de España, sino, principalmente, reforzar la moral y la creencia en la victoria, evocando $\mathrm{y}$ haciendo surgir en la mente del oyente $\mathrm{y}$, posteriormente, del lector, efectos de presencia. Asimismo, hemos podido explicar cómo algunos rasgos de este discurso poético, percibidos por algunos críticos como rémoras, como la «adopción de algunas creencias o mitologías populares (el mito de la virilidad, de la heroicidad desarmada, de los muertos que están más vivos que los vivos,

38. María Gómez y Patiño, Propaganda poética en Miguel Hernández. Un análisis de su discurso periodístico y político (1936-1939), Alicante, Instituto de Cultura Juan Gil-Albert, 1999, p. 449.

39. Ibid., pp. 465-466.

40. Hernández, Obra completa, p. 2166.

41. Ibid., p. 2057.

42. Julio Neira, «El poeta en la guerra», en F. J. Díez de Revenga y M. de Paco, eds., Un cósmico temblor de escalofríos. Estudios sobre Miguel Hernández, Murcia, Fundación Cajamurcia, 2010, p. 277. 
etc.) $\aleph^{43}$, se integran perfectamente dentro de la lógica de la producción de presencia.

Pero la integración de alguien como Miguel Hernández, dominado desde su juventud por «una casi extrahumana voluntad de ser poeta ${ }^{44}$ en el espacio de producción del frente como un miliciano más no estaba exenta de contradicciones. A veces, el poeta se separa de la comunidad para erigirse en portavoz de ésta y usar su competencia estética para expresar un discurso común. Así, en numerosas ocasiones, Hernández expresa su propósito de ser la voz de su pueblo. Por ejemplo, en su carta al Campesino, se declara «dispuesto a que mi voz sea la que nuestro pueblo mueve sobre nuestra garganta ${ }^{45}$. Sin embargo, esto ya supone una diferenciación, entre el poeta, individuo nacido con dones especiales, y el resto de combatientes, vistos como masa indiferenciada. El poeta de Orihuela no dedicó Viento del pueblo a los combatientes que iban a leerlo en las trincheras, sino a Vicente Aleixandre, con quien se identifica por encima de todos, pues «hemos nacido poetas entre todos los hombres». A pesar de que la expresión poética se había generalizado entre los combatientes, Miguel Hernández se considera destinado a ser el portavoz de éstos, del pueblo que "espera a los poetas con la oreja y el alma tendida al pie de cada siglo" para ser conducido "hacia las cumbres más hermosas» por los poetas ${ }^{46}$. Con ello, el oriolano caía en una concepción romántica del poeta, que José Díaz Fernández había reintroducido, declarando que «los artistas atisban antes que nadie las formas vitales del porvenir. Por algo los antiguos llamaron vate al artista más puro, al poeta lírico. Vate, es decir, adivino. La intuición es la atribución del genio, y genio, específicamente considerado, es el creador, el artista que por la gracia de su obra es semejante a un dios» ${ }^{47}$. Con su aspiración a ser «clamor de pueblo atropellado", Hernández negaba a los individuos que formaban este pueblo la capacidad para expresarse mediante sus propias voces, a pesar del surgimiento de numerosísimas «vocaciones incipientes» en las filas del Ejército popular ${ }^{48}$, gracias a las mencionadas campañas de alfabetización y extensión cultural. De hecho, en este aspecto, en los frentes de guerra, durante unos meses, se cumplió en gran medida la abolición de la división del trabajo y casi se realizó el sueño de Marx y Engels para quienes, en una sociedad comunista, no habría por ejemplo pintores, sino a lo mucho «hombres que, entre otras cosas,

43. Dario Puccini, Miguel Hernández. Vida y poesía y otros estudios hernandianos, Alicante, Instituto de Estudios Juan Gil-Albert, 1987, p. 74.

44. Concha Zardoya, «El mundo poético de Miguel Hernández», en María de Gracia Ifach, ed., Miguel Hernández, Madrid, Taurus, 1975, p. 109.

45. Op. cit., p. 2186.

46. Op. cit., p. 55-56.

47. José Díaz Fernández, Prosas, introducción y selección de Nigel Dennis, Madrid, Fundación Santander Central Hispano, 2006, p. 374. Lo cual no era sino un calco de la célebre definición que Shelley hiciera de los poetas como «mirrors of the gigantic shadows which futurity casts upon the present» $\mathrm{y}$ «unacknowledged legislator[s] of the world».

48. Serge Salaün, «Poetas "de oficio" y vocaciones incipientes durante la Guerra de España», en François Botrel y Serge Salaün, eds., Creación y público en la literatura española. Madrid, Castalia, 1974, p. 181-214. 
también pintan $»^{49}$. En el Ejército popular hubo muchos soldados que, entre otras cosas, también escribían versos, pero también hubo poetas, diferenciados de aquéllos por una idea mitificada de la poesía, necesaria por otra parte para las necesidades de la lucha.

Y sin embargo, a pesar de estas contradicciones, Miguel Hernández logró, de manera única a mi entender, y en ello radica una de las razones por las que su poesía de guerra sigue conmoviendo al lector actual, armonizar su proyecto creador y su idea sublime de la poesía, con una identificación igualitaria con los milicianos junto a los que combatía, al considerarse él mismo, como la mayoría de ellos, un campesino ${ }^{50}$. Miguel Hernández, al contrario que otros poetas, estaba dispuesto a aceptar el máximo sacrificio que exaltaba como necesario en sus poemas de guerra, y que terminaría sufriendo, pese a las inhumanas presiones que sufriría, con «la cabeza bien alta»:

\author{
Si me muero, que me muera \\ con la cabeza muy alta. \\ Muerto y veinte veces muerto, \\ la boca contra la grama, \\ tendré apretados los dientes \\ y decidida la barba. \\ Cantando espero a la muerte, \\ que hay ruiseńores que cantan \\ encima de los fusiles \\ y en medio de las batallas ${ }^{51}$.
}

49. Karl Marx y Friedrich Engels, Die deutsche Ideologie. Gesamtausgabe. Erste Abteilung, vol. 5., Berlin, Marx-Engels-Verlag, 1932, p. 373. La traducción es mía.

50. Como apuntó acertadamente Cecilio Alonso, Miguel Hernández «rindió su impulso poético más secreto a las exigencias de la conciencia colectiva y lo hizo sin perder su autenticidad. Y eso todavía hoy produce pasmo entre sus lectores». Cecilio Alonso, "Desclasamiento y mentalidad campesina en Miguel Hernández», en José Carlos Rovira, ed., Miguel Hernández, cincuenta años después. Actas del I Congreso Internacional. (Alicante, $25-28$ marzo 1992), Alicante, Comisión del Homenaje, 1993, p. 310.

51. Hernández, Viento del pueblo, p. 67. 


\section{BibliografíA}

Alonso Cecilio, «Desclasamiento y mentalidad campesina en Miguel Hernández», en José Carlos Rovira, ed., Miguel Hernández, cincuenta años después. Actas del I Congreso Internacional. (Alicante, 25-28 marzo 1992), Alicante, Comisión del Homenaje, 1993, pp. 305-310.

Balcells José María, Miguel Hernández, corazón desmesurado, Barcelona, Dirosa, 1975.

Bourdieu Pierre, "Une classe objet», Actes de la Recherche en Sciences Sociales, 17-18 (noviembre 1977), pp. 2-5.

— Les règles de l'art. Genèse et structure du champ littéraire, París, Éditions du Seuil, 1992.

Cano Ballesta Juan, La poesía de Miguel Hernández, Madrid, Gredos, 1962.

Chevallier Marie, La escritura poética de Miguel Hernández, Madrid, Siglo XXI, 1977.

— Los temas poéticos de Miguel Hernández, Madrid, Siglo XXI, 1978.

Díaz Fernández José, Prosas, introducción y selección de Nigel Dennis, Madrid, Fundación Santander Central Hispano, 2006.

Gaya Ramón, «Divagaciones en torno a un poeta: Miguel Hernández», Hora de España, 17 (abril-junio de 1938), pp. 143-151.

Gil-Albert Juan, «El poeta como juglar de guerra», Nueva Cultura, III, 1 (marzo 1937), pp. 252-253.

Gómez y Patińo María, Propaganda poética en Miguel Hernández. Un análisis de su discurso periodístico y político (1936-1939), Alicante, Instituto de Cultura Juan Gil-Albert, 1999.

Gumbrecht Hans-Ulrich, Diesseits der Hermeneutik. Die Produktion von Präsenz, Fráncfort del Meno, Suhrkamp, 2004.

Heidegger Martin, Sein und Zeit, Tubinga, Max Niemeyer Verlag, 2001.

Hernández Miguel, Viento del pueblo. Poesía en la guerra, edición de Juan Cano Ballesta, Madrid, Cátedra, 1989.

- Obra completa, vol. 2. Teatro. Prosas. Correspondencia, edición crítica de José Carlos Rovira y Agustín Sánchez Vidal, Madrid, Espasa-Calpe, 1992.

Herrera Petere José, Obras Completas. Narrativa I, edición crítica de Dolores Gimeno Puyol. Guadalajara, Diputación de Guadalajara y Junta de Castilla-La Mancha, 2009.

Le Bigot Claude, L'encre et la poudre: pour une sémantique de l'engagement dans la poésie espagnole sous la II. République (1931-1939), préface de Francisco Caudet. Toulouse, Presses Universitaires du Mirail, 1997.

Lechner Johannes, El compromiso de la poesía española del siglo XX. Parte primera. De la generación de 1898 a 1939, Leiden, Universitaire Pers Leiden, 1968.

Luis Leopoldo de, Aproximaciones a la obra de Miguel Hernández, Madrid, Libertarias/ Prodhufi, 1994.

Martín Eutimio, El oficio de poeta. Miguel Hernández, Madrid, Aguilar, 2010.

Martín Gijón Mario, «Verbreitung des Diskurses und Produktion der Präsenz. Das sprachliche Zeichen in der Dichtung des Spanischen Bürgerkrieges am Beispiel von José Herrera Petere, Emilio Prados und César Vallejo», Zeichen setzen. Konvention, Kreativität, Interpretation. 24 Forum Junge Romanistik 2008, ponencia inédita.

Marx Karl y Friedrich Engels, Die deutsche Ideologie, en Karl Marx y Friedrich Engels, Gesamtausgabe. Erste Abteilung, vol. 5., Berlín, Marx-Engels-Verlag, 1932.

Nancy Jean-Luc, The Birth to Presence, Stanford, Stanford University Press, 1993. 
Neira Julio, «El poeta en la guerra», en Francisco Javier Díez de Revenga y Mariano de Paco, eds., Un cósmico temblor de escalofríos. Estudios sobre Miguel Hernández, Murcia, Fundación Cajamurcia, 2010, pp. 265-288.

Ong Walter J., Orality and Literacy. The Technologizing of the Word, Londres: Routledge, 2002.

Puccini Dario, Miguel Hernández, Vida y poesía y otros estudios hernandianos, Alicante, Instituto de Estudios Juan Gil-Albert, 1987.

Salaün Serge, "Poetas "de oficio" y vocaciones incipientes durante la Guerra de Espańa», en François Botrel y Serge Salaün, eds., Creación y público en la literatura española. Madrid, Castalia, 1974, p. 181-214.

— «Miguel Hernández: Individualidad y colectividad», en Juan Cano Ballesta y otros, En torno a Miguel Hernández, Madrid, Castalia, 1978, pp. 184-212.

— «La guerre d'Espagne ou l'épopée du signe», Imprévue IX, 2 (1986), pp. 19-36.

— «Miguel Hernández: Eros en la guerra (Viento del pueblo)», en Francisco Javier Díez de Revenga y Mariano de Paco, eds., Estudios sobre Miguel Hernández, Murcia, Universidad de Murcia, 1992, pp. 433-446.

Vera Abadía Manuel Ramón, «Miguel Hernández en el laberinto de la guerra civil», Anthropos, 220 (2008), pp. 42-48.

Vivanco Luis Felipe, «La desesperación en el lenguaje», Cruz y Raya, 8 (noviembre 1933), pp. 149-158.

Zardoya Concha, «El mundo poético de Miguel Hernández», en María de Gracia Ifach, ed., Miguel Hernández, Madrid, Taurus, 1975, pp. 109-117.

Zumthor Paul, Introduction à la poésie orale, París, Éditions du Seuil, 1983. 